\title{
The health-improving and professionally applied aspect of physical culture in the training of agro-industrial complex personnel
}

\author{
Lyudmila Demyanova ${ }^{1}$, Olga Mavropulo ${ }^{1}$, and Irina Usova, ${ }^{2, *}$ \\ ${ }^{1}$ Don State Technical University, 1, Gagarin sq., 344003, Rostov on Don, Russia \\ ${ }^{2}$ Institute of Technology (branch) DSTU in Volgodonsk, 16, st. Mira, 347386, Volgodonsk, Rostov \\ Region, Russia
}

\begin{abstract}
This scientific and theoretical article is devoted to the consideration of the problem of the implementation of sports and recreational technologies in order to make recommendations on the adjustment of their practical application. The basic principles of the use of payroll in practice were clarified. The novelty of the article is due to its applied orientation.
\end{abstract}

\section{Introduction}

Student health is one of the main values of modern higher education and it depends on the health-improvingtechnologiesimplemented at the university [1]. However often student low rates of physical training and low indicators of his health are not due to the form and content of the health-improving technologiessince most of them (bodybuilding, swimming, fitness etc.) were developed by leading experts in the field of sports using latest advances in science and technology. In the opinion of I. V. Babich the problem of the inefficiency of the health-improving technologiesis associated with their illiterate application directly in practice [2].

In an article by scientists of the university named after P.F. Lesgaft describes progress in ongoing research projects to develop theoretical principles for the development of physical education and sports, with particular attention to physical education and the availability of sports services, inclusiveness and system design. It should be noted that the project focuses on the strategic planning system for physical education and sports in order to stimulate various future initiatives [3].

Sadovnikova E.S. studies the principles of the functioning of the youth sports and fitness system at the university and one of many features are formulated: the need to constantly maintain the conviction of youth in the advisability of performing sports and fitness activities [2].

*Corresponding author: irina_usova@mail.ru 


\section{Sport and health-improving technologies in the training of agro-industrial complex personnel}

Throughout the history of human development sport has played a special role in our lives. It was believed that playing sports gives a person the surest opportunity to have good health. However, despite the prevailing stereotype of a similar miraculous power of a sports lifestyle there are a large number of contradictions that must be taken into account. Firstly in addition to sports a person's health is affected by his daily routine, the amount of nightly sleep, diet, the environmental condition of the area in which he lives, the presence of stressful situations or addictions, heredity and much more. For this reason it is almost impossible to conclude that sport is the only way to health. In addition, there are enough cases where excessive loads led to injuries or even death either during the competition or immediately after them. An example is Ray Chapman, who was fatally injured in a baseball game, or Bill Masterton, who died 2 days after an injury received during a hockey game. A lot of injuries happen in boxing championships. One of the most famous cases is the fight between boxer Edward Sanders in 1954 which also ended fatally.

As a review of the scientific literature has shown a modern student recognizes the importance of health and the need to maintain it and is also aware of the connection between health and physical education, however the lack of a conscious need for physical activity is due to unmotivated students due to certain reasons that affect in particular the effectiveness of the implementation of the health-improving technologies [4]. There are some of them:

1) insufficiency of the theoretical basis of a student physical education;

2) underdevelopment of psycho-physiological needs in motor and cognitive physical culture activity;

3) a weak creative and reflective component of physical culture;

4) psychological blocks [5].

Ignorance of the theoretical bases leads the students to the denial or misunderstanding of the material, spiritual, aesthetic, psychological, social and individual values of physical culture. In addition, students do not have necessary physical education knowledge, skills and abilities, and it in its turn reduces the motivation for learning and realizing the practical side of physical development culture which negatively affects the effectiveness of using any the health-improving technology [6].

The solution of this problem is the comprehensive training of students for the theoretical foundations of physical culture as a complex phenomenon aimed however directly at the applied use of acquired knowledge in practical classes and in everyday life.

Motivation is a set of motives prompted by needs which appear in a person in the form of desires and inclinations. There are material, spiritual and social needs. The dissatisfaction of any needs leads to the activation of the organism, howeveron the contrary the prolonged dissatisfaction of needs gives rise to apathy [7]. The same phenomena is observed among students who study at the different agro-industrial complex departments.A sedentary lifestyle reduces the activity of the body motor activitymoreover according to the results of this category of students research physical culture and sport are not associated with the satisfaction of any need (material, spiritual, social) and this fact causes their complete indifference to physical activity in general and the implementation of healthimproving technologies in particular.

To overcome students disinterest in physical training it is necessary to satisfy such needs as:

1) material: high-quality sports equipment, convenient area for classes etc.

2) spiritual: cognitive, creative activity, self-development, self-knowledge, spirituality, personal growth etc. 
3) social: communication and interaction with people, public recognition etc.

4) physical: the development of the body, its functionality, properties and qualities, the acquirement of new skills and abilities etc.

A modern student engaged in a specific health-improving technologyis often indifferent to it, since his program is deprived of creative freedom, and physical activity is deprived of awareness. However it is known that a person is the best teacher for himself, it is also known that his contribution to a particular work increases his interest in the latter and helps to strengthen his motivation for active work [8]. That is why we think it is necessary:

1) to make the student the creator of his physical culture. It is necessary to equip him with all the necessary knowledge, skills and abilities and then allow to use them freely to build a student culture of physical development. In this case the teacher is given the role of a mentor who monitors the process of formation and implementation of the student's physical culture and monitors the results of the student's independent activity, correlating goals and objectives with the means and methods of their implementation.

2) It is required to make the student's physical activity conscious: it is necessary to train him in sports reflection, i.e. to teach a student to observe, analyze and evaluate his own physical activity. This means that the student becomes a teacher for himself who is able to compose, implement and control his physical education activities.

Such an approach to physical education will increase the level of motivation for any student significantly, even the most disinterested one.It will provide the best conditions for the effective implementation of physical education.

It is necessary to recognize that a certain part of students shows low efficiency in the process of implementation of health-improving technologies due to various psychological blocks in the field of physical culture [9]. Physical education for such students is primarily associated with humiliation, bad mood, etc. This attitude is often formed because of the following reasons:

1) existence of sports failures and related experiences,

2) unsuccessful sports past, i.e. the student's physical activities were condemned or ridiculed by someone, it caused a negative impression;

3 ) all kinds of complexes associated with the process of physical activity itself or with attitude to one's body, one's appearance etc.

The solution of this kind of problem can be psychological assistance to the student, as well as a special sparingconditions of classes with a gradual approximation of the latter to the standard of putting health-improving technologies into effect. In addition such students may require a special approach from the standpoints of sports psychology which includes the correction of negative attitudes and the creation of a positive attitude to physical culture in general and to themselves as an integral part of the latter.

The target orientation of any health-improving technology is to create, strengthen and improve the health of the student and physical fitness activities are of great importance for the implementation of this aim, however, $50 \%$ of the level of health depends on the individual's lifestyle. Not a health-improving technology will bring the desired results if the student will combine the implementation of this program with an unhealthy lifestyle and on the contrary the combination of the health-improving technologies with maintaining a healthy lifestyle will greatly improve the results of using the physical culture and healthimproving technology and increase the student's health indicators [10].

A healthy lifestyle can be defined as a combined system that implies reasonable immunity to bad habits (smoking, alcohol and drugs), good relaxation, healthy eating, effective physical activity combined with relaxation, walking in the fresh air, an appropriate health program, goals and Most importantly, motivation.

The first-year students $(n=761$, including 482 men and 279 women $)$ and the third-year students $(\mathrm{n}=829$, including 447 men and 382 women), whose values and motives for a 
healthy lifestyle were examined using a survey, were selected for the survey. The age difference in the sample was designed to measure progress or regression in each motivation for a healthy lifestyle with age. The survey data were interpreted as evidence that senior students are more decisive about healthy lifestyle issues (obviously due to better physical education skills), they are more active in physical education activities outside of school and more effective in managing time, healthy eating and healthy daily routine [11].

However the most students have an unhealthy lifestyle. They have not formed valeological thinking, i.e. consciousness of responsibility for one's health and valeological activity of an individual [12]. Our observations helped us to go the following conclusion that the modern student who studies at the different agro-industrial departments is inclined to make external factors responsible for his health and display neither mental nor physical activity to take care of his health.

From this point of view most students belong to the following valeological types:

1) supporting type (high locus control, low activity);

2) manipulative type (high activity, low level of locus control);

3) deficit type (weak locus control, low activity).

The self-regulatory type (all indicators are normal) is extremely rare, but people of this type only lead a healthy lifestyle and they have much better results the health-improving technology which they perform. That is why for the best effectiveness of the healthimproving technology it is necessary to create a healthy lifestyle for each student through the development of self-regulatory type personal qualities in university students namely a high level of responsibility for their health (to themselves and to society) and sufficient activity to maintain health [13].

A review of various scientific approaches to the formation of healthy lifestyle showed the fexpediency of the following measures $[14,15]$ :

1) the correction of bad habits already formed among students and the correction of their lifestyle in general, aimed at harmonizing the latter;

2) teaching students methods of successful social and psychological adaptation;

3) teaching students the basics of health and life (valeological approach).

A survey of 55 students including 8 boys (14.5\%) and 47 girls $(85.4 \%)$ found that the number of patients who did not get sick during the year was $3.3 \pm 1.3 \%$ among the boys and $15.6 \pm 1.2 \%$ among the girls. The primary morbidity rate among young boys was 150.0 \pm 3.9 cases and among girls was $253.0 \pm 3.6$ cases per 100 first-year students. Among the students of the first three courses, the highest incidence rate was observed among the firstyear students, it was $326.0 \pm 3.5$ cases per 100 examined (Figure 1).

In the structure of primary morbidity, acute respiratory diseases, rhinitis and tonsillitis are on the first place. The prevalence rate of chronic diseases was $87.5 \pm 0.4$ cases among boys and $50.9 \pm 0.9$ cases among girls. Chronic gastritis is in the structure of the chronic incidence.

It is necessary to solve the problems of improving the health of students by means of prevention, protecting the health of healthy people by organizing a healthy lifestyle, physical education and sports. 
index rates of chronic morbidity

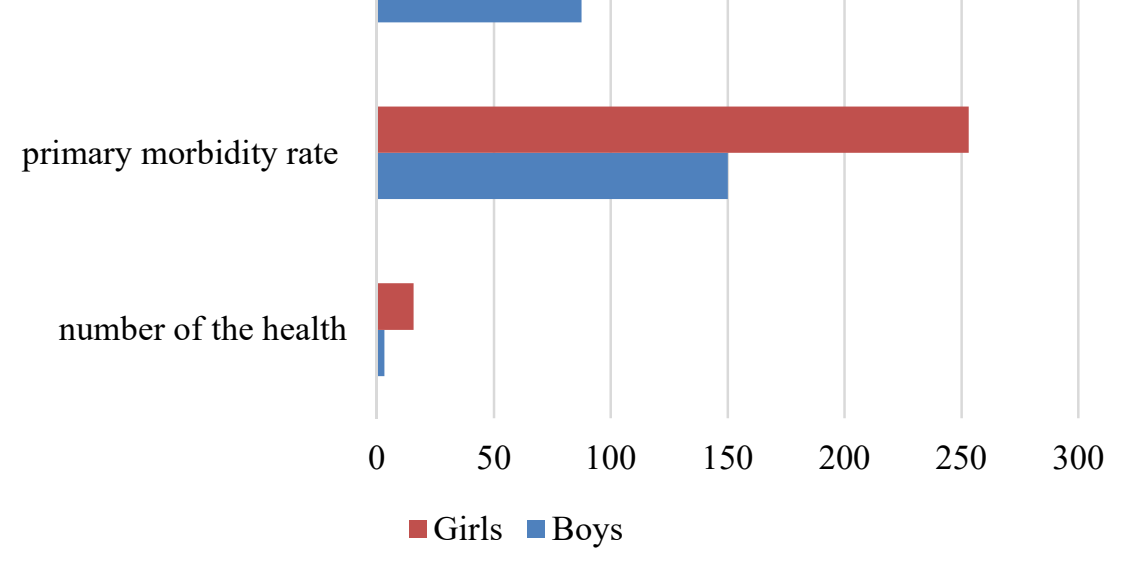

Fig. 1. Health indicators of the 1-3 courses students.

\section{Conclusion}

Thus the motivation and maintaining a healthy lifestyle have a huge impact on the effectiveness of the implementation of sports and fitness technologies in physical education for a modern student who study at the different agro-industrial departments.Motivation stimulates students' interest in fundamental theoretical knowledge and the most effective practical application of health-improving technologies. Maintaining a healthy lifestyle increases the physical potential of students and contributes to better achievement, development and lasting consolidation of the results of their application of healthimproving technologies.

The recommendations made during the study have significant theoretical potential for further study. In addition, they have an applied orientation and can be used in practice for the direct effective use of any health-improving technology.

\section{References}

1. S.E. Bakulev, V.A. Taymazov, S.M. Ashkinazi, A.N. Kochergin, V.V. Ryabchikov, Theory and practice of physical education and sports 2, 3-5 (2019)

2. E.S. Sadovnikov, Theory and practice of physical education 3, 70-76 (2019)

3. A.N. Alenova, V.G. Shubovich, I.O. Petrishchev, Theory and Practice of Physical Culture and Sports 3, 52-54 (2019)

4. O.I. Myakisheva, G.V. Valeeva, E.V. Prokhorova, V.A. Khadzhimamedova, Theory and Practice of Physical Culture and Sports 3, 25-31 (2019)

5. S.V. Kakhnovich, V.V. Izvekov, K.V. Izvekov, Physical Culture in a holistic process of personality formation 2, 52-58 (2019)

6. O. Mavropulo, E. Muryukina, Media education 1, 95-100 (2018)

7. V.K. Balsevich, Physical education: upbringing, education, training 1, 23-28 (2015)

8. S.Yu. Barinov, Bulletin of sports science, The concept of sports culture of personality 

6, 17-24 (2014)

9. K.D. Chermit, A.L. Dude, Bulletin of the Adygea State University. Series 3 Pedagogy and Psychology 4, 184-186 (2013)

10. G.L. Kravtsova, Features of the formation of a healthy lifestyle for schoolchildren, 8490 (2016)

11. V.A. Grekhovodov, Analysis of modern concepts in scientific pedagogical research 9 , 21-25 (2013)

12. L.M. Smirnova, N.O. Smirnova, M.V. Gelas, L.V. Krylov, Improving the physical education of schoolchildren in the system of a comprehensive school, 65-69 (2018)

13. N.I. Nikolaev, S.V. Vaserman, L.N. Misheneva, A.A. Belisova, E.A. Kronshtatova, Healthy Lifestyle in Modern Society, 54-58 (2017)

14. S.A. Druzhilov, Healthy Lifestyle as Appropriate Human Activity 4, 32-35 (2016)

15. L.E. Pantyukhina, A.S. Makhov, A.P. Matveev, J.Yu. Seagull, Scientific and theoretical journal "Scientific notes of the University named after P.F. Lesgaft" 7(125), 206-2012 (2015) 